\title{
Niğde İlinde Güneş Enerjisi Santrallerinin Yaygınlaştırılması ve Sera Gazı Emisyonlarının Azaltılmasının Potansiyeli
}

\author{
Tufan SAK ${ }^{1}$, Çağdaş GÖNEN², Emine Erman KARA ${ }^{3 *}$ \\ 1,2,3Niğde Ömer Halisdemir Üniversitesi, Mühendislik Fakültesi, Çevre Mühendisliği Bölümü \\ Adres: Niğde Ömer Halisdemir Üniversitesi, Müh. Fak., Çevre Müh. Böl., 51240, Niğde, Türkiye \\ 1'tufansak@gmail.com, ${ }^{2}$ cagdas.gonen@ohu.edu.tr, ${ }^{3}$ eerman@ohu.edu.tr
}

\begin{abstract}
Öz: Günümüzde modern toplumların elektrik enerjisi ihtiyacını karşılamak için kullanılan fosil türevli yakıtlardan hızla doğa dostu olan yenilebilir enerji kaynaklarına geçilmektedir. Fosil türevli yakıtların kullanılması sonucunda biriken sera gazları nedeniyle küresel iklim değişikliği ortaya çıkmıştır. Bunu yanında hava kalitesi de bozulmaya başlamıştır. Güneş enerjisi ekonomik ve teknik uygulanabilirlik açısından en yaygın olarak tercih edilen yenilebilir enerji kaynağı olarak günümüzde kabul görmektedir. Yapılan bu çalışmada Niğde ili için güneş enerjisinin elektrik enerji üretimli potansiyeli, ekonomik ve çevresel olarak uygulanabilirlik açısından incelenmiştir. İldeki mevcut arazi kullanım haritaları, tarım arazileri ve güneş radyasyon potansiyeli haritaları bir arada değerlendirilmiştir. İldeki tarım arazisi ve orman vasfını yitirmiş alanın sadece $\% 3,4$ güneş enerjisi üretimi için kullanıldığında gerekli olan elektrik enerjisi ihtiyacı karşılanabileceği hesaplanmıştır. Bu enerji yılda 435924 ton $\mathrm{CO}_{2}$ emisyonun atmosfere verilmeyeceği anlamına gelmektedir.
\end{abstract}

Anahtar kelimeler: Yenilenebilir enerji, Sera gazları, Güneş Enerjisi, İklim değişikliği.

\section{Dissemination of Solar Power Plants in Niğde Province and Potential for Reducing Greenhouse Gas Emissions}

\begin{abstract}
Today, fossil-derived fuels are used to meet the electricity needs of modern societies, and quickly switch to environmentally friendly renewable energy sources. As a result of the use of fossil-derived fuels, global climate change has increase due to the accumulation of greenhouse gases. Besides this, the air quality has started to deteriorate. Solar energy is now accepted as the most widely used renewable energy source in terms of economic and technical viability. In this study, solar energy potential for Niğde city province was examined in terms of potential, economic and environmental viability of electrical energy production. Current available land use maps, agricultural landmarks and solar radiation potential maps have been evaluated together. It is calculated that the required electricity energy requirement can be met when the current nonagricultural land and the non-forest land are used for only 3.4\% solar energy production. This means that 435924 tons of CO2 emissions per year will not be given to the atmosphere.
\end{abstract}

Key words: Renewable energy, Greenhouse gases, Solar power, Climate change.

\section{Giriş}

Enerjinin üretimi ve tüketimi İlk çağlardan beri insan hayatında önemli yer bulmuştur. Günümüze kadar gelen süreçte enerjinin üretim ve tüketim şekli birbirinden farklı olsa da günlük hayattaki faaliyetlerin devamı ve gelişmenin sürekliliği için enerjiye ihtiyaç duyulmuştur. Modern hayatla birlikte nüfus artışı da enerjiye olan talebi arttırmıştır. Sanayinin gelişmesi ve nüfusun artmasıyla oluşan enerji üretim ve talebindeki baskı, ülkeleri daha çok enerjiyi ekonomik yöntemlerle üretmeye doğru yönlendirmiştir. Bu baskı, bir yandan dünyada politik çatışmalara sebep olurken, diğer yandan doğal kaynakların aşırı tüketilmesine ve buna bağlı olarak çevre kirliliğinin oluşmasına neden olmuştur [1-3]. Enerji, ülkelerin sürdürülebilir bir şekilde kalkınmaları ve gelişmeleri için en önemli unsurlardan birisidir. Bunun en ekonomik şekilde sağlanabilmesi için, enerjinin yenilenebilir kaynaklardan sürdürülebilir bir şekilde ve doğa dostu yöntemlerle elde edilmesi şarttır. Özellikle enerjinin yerel ve yenilenebilir kaynaklardan elde edilmesi kalkınmada en önemli nokta olan sanayi üretiminin katma değerinin daha yüksek olabilmesine yardımcı olacaktır $[4,5]$.

Sanayi devrimi sonrasında teknolojinin hızla gelişmesi ve nüfusun katlanarak artışı ile enerjiye olan talep artmıştır. $\mathrm{Bu}$ artışın yarattığı baskılar sonucunda fosil türevli enerji kaynakları aşırı derecede kullanılarak tüketilmiştir. Fosil türevleri kaynaklarının uzun yıllar boyunca 1sınma, elektrik enerjisi üretimi ve ulaşım ihtiyaçlarının giderilmesi için yoğun olarak üretilmesi ve tüketilmesi sonucunda en büyük çevre etkisi olan iklim

\footnotetext{
*Sorumlu yazar: eerman@ ohu.edu.tr. Yazarların ORCID Numaras1: ${ }^{1}$ 0000-0003-2994-012X, ${ }^{2}$ 0000-0002-8554-8125, ${ }^{3} 0000-0002-9075-$ 0563
} 
değişikliği geri dönülemez bir şekilde karşımıza çıkmıştır [6]. Fosil yakıtların yanması sonucunda karbondioksit ve azot oksit gazları uzun yıllar boyunca açığa çıkmıştır. Sera etkisi yaratan bu gazların atmosfere salınmaları sonucunda atmosferdeki konsantrasyonları olması gereken doğal seviyenin üzerine çıkmıştır. Fosil türevli enerji kaynaklarından gelen ilave sera gazlarının atmosfere birikmesi sonucunda yeryüzü sıcaklığı olması gerekenin $1^{\circ} \mathrm{C}$ üzerine çıkmıştır. Bu artış günümüzde hala devam etmekte olup, geri dönülmez bir çevre felaketine dönüşmek üzeredir. Bu çevre etkisi yanında fosil türevli yakıtların kullanıldığı bölgelerde hava kalitesinin aşırı derecede düştüğü ve insan sağlığının olumsuz şekilde etkilendiği de bilinmektedir. Tarım yapılan bölgelerde fosil yakıtların kullanılması sonucunda ortaya çıkan gaz ve taneciklerin tarımsal ürünlerin verimliliğini de düşürdüğü bilinmektedir [1, 2, 7].

Elektrik enerjisi üretimi, ulaşım ve ısınma gibi ihtiyaçların karşılanması için ömürleri sınırlı olan fosil yakıtlara alternatif enerji kaynaklarının geliştirilmesi kaçınılmazdır. Bu alternatif enerjilerden güneş enerjisi, rüzgar enerjisi ve biyokütle enerjisi en yaygın kullanılan türleridir. Bunlara ilave olarak jeotermal enerji, dalga enerjisi ve hidrojen enerjisi gibi yenilenebilir ve sürdürülebilir enerji kaynakları atmosfere ilave sera gazı emisyonu oluşturmadıkları için doğa dostudurlar [8]. Ayrıca, fosil türevli yakıtların oluşturduğu ortalama sıcaklık artışının devam etmesini engelleyebilme potansiyelleri de mevcuttur. İklim değişikliği ile mücadele edebilmek ve küresel ısınma artışını durdurabilmek için uluslararası ölçekte Birleşmiş Milletler ve Avrupa Birliği'nin birçok çalışması ve programı mevcuttur. Bu çalışma ve programlar içerisinde Türkiye etkin bir şekilde yer almaktadır [9]. Uluslararası ölçekte alınması planlanan tedbirlerin başında elektrik enerjisi üretiminde, ulaşım amaçlı kullanılan fosil yakıtların kullanımının sınırlandırılması, yerine alternatif ve yenilenebilir enerji kaynaklarının kullanılmasının teşvikleri gelmektedir. Enerji kaynağının yanında yenilikçi teknolojiler geliştirilerek daha düşük enerji tüketen araçların ve cihazların yapılması teşvik edilmektedir. Bunlara ilave olarak daha az atık üreten teknolojiler ve daha az atığa neden olan ürünlerin geliştirilmesi teşvik edilmektedir $[3,7,10,11]$. Türkiye'de bahsedilen konuda birçok tedbir uygulamasına başlanmıştır. Elektrik enerjisi üretiminde yenilenebilir kaynakların kullanılması halinde teşviklerin uygulanabilmesi için yönetmelikler yürürlüğe girmiştir. Bunun yanında rüzgar enerjisi ve güneş enerjisi için enerji ihtisas bölgeleri belirlenmiş ve buralarda büyük ölçeklerde enerji üretimine başlanmıştır. Bu uygulamaların yanında Ulusal sıfır atık Eylemi Çevre ve Şehircilik Bakanlığı tarafından yürürlüğe konmuştur. Böylelikle atıkların bertarafı ve çürümesi sırasında oluşacak sera etkisi yaratan karbondioksit ve metan gazı emisyonları kontrol altına alınabilecektir [5, 9, 12, 13].

Dünya'da güneş enerjisinden elektrik üreten fotovoltaik sistemler son yıllarda hızla gelişmiştir. Yenilenebilir enerji pazarında fotovoltaik sistemler büyük yer tutmuştur. Son yıllardaki bu teknolojik gelişmelere ve iklim değişikliği konusunda doğa dostu enerji üretim teknolojilerine olan ihtiyaca paralel olarak Türkiye'de güneş enerjisi kullanımı öncelikli olarak teşvik gören alanlara girmiştir. Türkiye'nin sahip olduğu mevcut coğrafi konumu sebebiyle enerji üretimi açısından birçok gelişmiş ülkeye göre çok verimlidir. Türkiye'nin özellikle güney ve güneydoğu kesimleri diğer bölgelerinden biraz daha yüksek güneş enerji potansiyeline sahiptir [8, 13].

Yapılan bu çalışmada Türkiye'nin güneyinde konumlu olan Niğde ili için sürdürülebilir ve yenilenebilir enerji kaynağı olan güneş enerjisinin elektrik enerji üretimli potansiyeli, ekonomik ve çevresel olarak uygulanabilirlik açısından incelenerek ortaya konmuştur. Bu çalışma kapsamında mevcut arazi kullanım haritaları, tarım arazileri ve güneş radyasyon potansiyeli haritaları bir arada değerlendirilerek hesaplamalar yapılmış ve öngörülerde bulunulmuştur. Güneş enerjisinden elektrik üretim potansiyeli yanında elde edilen bu enerjinin iklim değişikliğine olan etkisi fosil türevli elektrik enerjisi üretim yöntemleri ile kıyaslamalı olarak hesaplanmıştır.

\section{Materyal ve Metot \\ 2.1. Çalışma bölgesi hakkında genel bilgiler}

Çalışmanın yapıldığı Niğde İli deniz seviyesinden $1300 \mathrm{~m}$ ortalama yükseklikte olan ve $77955 \mathrm{~km}^{2}$ alana yerleşik alandadır. T.C. Gıda Tarım ve Hayvancılık Bakanlığı verilerine göre arazi kullanım sınıflarına göre 8 farklı sınıfta sınıflandırılmıştır. Niğde ilinde I. ve IV. kategori arasındaki sınıflarda 262.577 ha. arazi mevcutken V. ve VIII. sınıflarındaki tarım arazilerinin alanı 516.945 ha'dır [14]. 


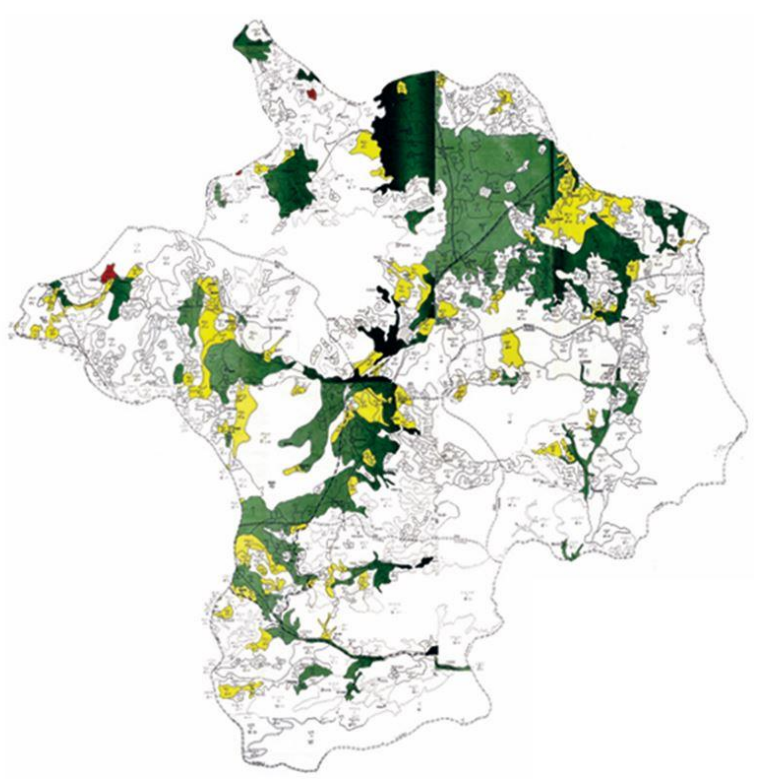

Şekil 1. Niğde ilinin arazi dokusunu gösteren harita (Yeşil: I. sınıf tarım alanları, Sarı II. sınıf tarım alanları, Kırmızı: III. sınıf tarım alanları, Beyaz: diğer tür alanlar).

Niğde Çevre ve Şehircilik İl Müdürlüğ̈̈’nden ve Niğde ili Gıda, Tarım ve Hayvancıllk il müdürlüğü’nden alınan verilere göre hazırlanan Tablo 2' de Niğde ilindeki arazı sınıfları, alanları ve toplam alana oranları verilmiştir.

Tablo 1. Niğde ilindeki arazi sınıfları, alanları ve oranları

\begin{tabular}{|c|c|c|}
\hline Arazi Türü & Oran (\%) & Alan (ha) \\
\hline I. sinıf & 5,85 & 45.674 \\
\hline II. sınıf & 11,70 & 91.053 \\
\hline III. sinıf & 6,30 & 49.061 \\
\hline IV. sinıf & 9,85 & 76.789 \\
\hline V.-VIII. sinıf & 66,30 & 516.945 \\
\hline
\end{tabular}

\subsection{Niğde ilindeki elektik enerjisi tüketim değerleri}

Niğde ilinde yıllık elektrik enerjisi tüketimi yaklaşık olarak 985.000 KWH'dır. İ'de konut alanları, ticaret haneler, evler, tarımsal sulama ve sokak aydınlatması amaçlı tüketilen elektik enerjisi sırasıyla yıllık 387.567 MWH, 218.696 MWH, 150.450 MWH, 135.956 MWH ve 24.596 MWH'dir. Niğde ilinde kişi başına tüketilen elektrik enerjisi 437 KWH'dir [14].

\subsection{Niğde ilinin güneș enerjisi potansiyeli}

Niğde ilinde 9 adet Güneş enerjisi santrali mevcuttur. 18,08 MW toplam kapasitesi bulunan 7 adet tesis aktif olarak çalışmakta ve 9,72 MW Kurulu kapasiteye sahip inşaat halinde tesis bulunmaktadır. Geçmiş yılların ortalama değerleri dikkate alındığında Niğde ilinde en uzun güneşlenme süresi Temmuz ayında ve 12,16 saattir. En kısa güneşlenme süresi ise Aralık ayında 3,90 saat olarak tespit edilmişsir. Niğde ilinde ortalama güneşlenme süresi ise 8,03 saattir. Yenilebilir enerji genel müdürlüğünden (YEGM) alınan verilere göre, Niğde ili Ulukışla ilçesinde güneşten gelen en düşük radyasyon seviyesi $1.500-1.550 \mathrm{KWH} / \mathrm{m}^{2}$ arasında, güneşten gelen en yüksek solar radyasyon Çamardı ilçesinde $1.750-1.800 \mathrm{KWH} / \mathrm{m}^{2}$ arasındadır. Ortalama yıllık solar radyasyon seviyesi Niğde ilinde $1650 \mathrm{KWH} / \mathrm{m}^{2} \operatorname{dir}[12]$. Niğde iline ait Güneş potansiyeli şekil 2'de verilmiştir [14]. 


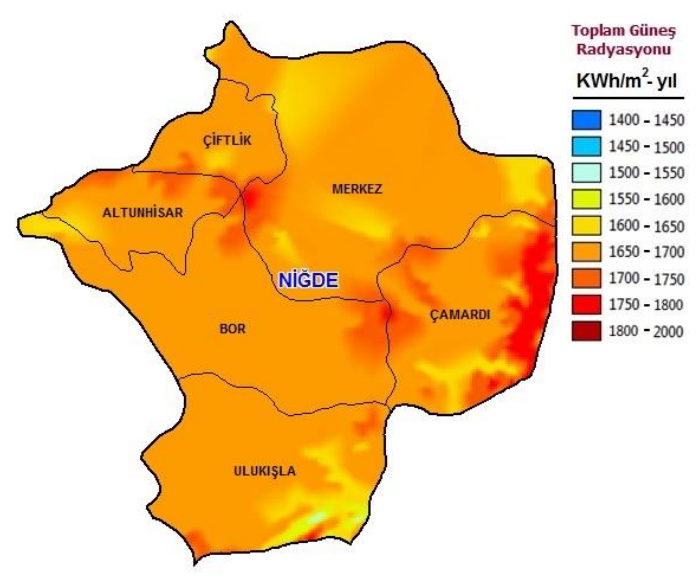

Şekil 2. Niğde İli Solar Radyasyon Haritası

\subsection{Niğde ilindeki farklı solar paneller için elektrik üretim potansiyelleri}

En bilinen ve yaygın olarak kullanılan panel türleri monokristalin silikon, polikristalin silikon, ince tabaka bakır ve amorf yapılı kristal panellerdir [12]. Niğde ili için YEGM alınan verilerden yapılan hesaba göre, bahsedilen bu panellerden $100 \mathrm{~m}^{2}$ de alınacak elektrik enerjisi Tablo 2' de verilmiştir [14].

Tablo 2. Niğde ilinde fotovoltaik panel türlerine göre yıllık üretilebilecek elektrik enerjisi potansiyelleri

\begin{tabular}{|c|c|}
\hline Fotovoltaik panel türü & $\mathbf{1 0 0 m}^{\mathbf{2}}$ den Ylllı elektrik enerjisi üretimi \\
\hline Mono kristalin silikon & $27.000 \mathrm{KWH}$ \\
\hline Polikristalin silikon & $24.000 \mathrm{KWH}$ \\
\hline İnce tabaka bakır & $14.000 \mathrm{KWH}$ \\
\hline Cadmium tellurium & $12.000 \mathrm{KWH}$ \\
\hline Amorf yapılı kristal paneller & $11.000 \mathrm{KWH}$ \\
\hline
\end{tabular}

Tablo 3 de verilen değerler dikkate alınarak yapılan hesaplama sonucunda Niğde ilindeki elektrik enerjisi tüketimi Türkiye'deki elektrik enerjisi tüketiminin \%0,5'ine eşittir. İlde kurulu elektrik enerjisi gücü (termal elektrik santrali, hidroelektrik santrali ve yenilenebilir) 10,35 MW dır. Bu ise, Türkiye'deki elektrik üretim değerinin \%0,01'ine denktir. Tablo 3' de Türkiye ve Niğde iline ait kurulu elektrik enerjisi üretim kapasiteleri verilmiştir.

Tablo 3. Niğde ilindeki elektrik tüketim ve üretim değerleri [14]

\begin{tabular}{|l|l|l|l|}
\hline Nüfus & 346.114 & Rüzgar enerjisi kurulu gücü & 0 \\
\hline Elektrik Tüketimi & $984.394 \mathrm{MWH}$ & Hidroelektrik santrali kurulu gücü & $0,069 \mathrm{MW}$ \\
\hline Türkiye'deki Elektrik tüketim payı & $0,50 \%$ & Jeotermal enerji kurulu gücü & 0 \\
\hline Niğde ilindeki kurulu güç & $10,35 \mathrm{MW}$ & Termal elektrik tesisi kurulu gücü & $10,28 \mathrm{MW}$ \\
\hline
\end{tabular}

\section{Sonuçlar}

Bu çalışmada Niğde ilindeki güneş enerjisinden elektrik üretim potansiyeli ve güneş enerjisinden elektrik üretimi sayesinde iklim değişikliğine sebep olan $\mathrm{CO}_{2}$ emisyonlarının azaltılma potansiyeli incelenmiştir. Bunun yanında, güneş enerjisi sisteminin kullanılması ile ede edilecek çevresel fayda ve ekonomik kazançlarda tanımlanmıştır. 
Yenilenemeyen fosil türevli enerji kaynaklarının küresel 1sınma, iklim değişikliği ve hava kalitesi gibi çevresel unsurları olumsuz etkilediği araştırma sonuçları ile ortaya konmuş bir gerçektir. Niğde ilinde de endüstri sahaları ve konut sahalarının ısıtılması ile ulaşım amaçlı tüketilen fosil türevli yakıtlar direk olarak hava kalitesini olumsuz etkilemektedir. Özellikle kış dönemlerinde ısınma amaçlı tüketilen doğal gaz, akaryakıt ve kömürden kaynaklı partikül ve kükürt seviyeleri çok yüksek olmaktadır. Fosil türevli enerji sistemlerine kıyasla güneş enerjisi sistemleri olan fotovoltaik sistemler hiç bir şekilde sera gazı emisyonu, hava kalitesini düşüren partikül veya atık yaratmamaktadır $[15,16]$. Üstelik fotovoltaik sistemlerin kullanım ömürleri bittiğinde kullanılan hammaddeler geri dönüştürülebildiklerinden yaşam döngüleri açısından bakıldığında da sürdürülebilir oldukları görülmektedir. Güneș enerjisi gibi yenilenebilir sistemler kullanıldığında o bölgedeki fosil türevli kaynakların sebebiyle bozulmuş olan hava kalitesi de zaman içerisinde olumlu yönde düzelebilmektedir $[17,18]$.

Güneş enerjisinden elektrik üretiminde fotovoltaik panellerin kullanımı için en önemli olan nokta, sistemin kurulacağı arazinin elverişliliğidir. Eğer arazi tarımsal uygulamalar için tanımlanmış ve tarımsal uygulamalar için elverişli ise o bölge üzerine her hangi bir tesis kurulmasına izin verilmez. Bu durum kanun ve yönetmelikler ile tanımlanmış ve yasaklanmıştır.

\subsection{Niğde ilinde arazi kullanımları ve güneş enerjisi potansiyeli eşleştirmesi}

Tarımsal alanların kullanımında gıda üretimi amaçlı kullanım öncelikli olmaktadır. Niğde'de 779522 hektar arazi olmasına rağmen, bunun sadece 98175 hektarı yenilenebilir enerji tesisleri kurulması için uygundur. $\mathrm{Bu}$ alanlar tarımsal faaliyetler için uygun olmayan ve orman vasfını yitirmiş olan alanlardır. Bu araziler topoğrafya açısında elverişli, ekonomik parametreler mümkün, yasal yapı ve sahiplik durumları gibi durumlar uygun ise yenilenebilir enerji tesisleri için gelecekte kullanılabilecek alanlardır.

Niğde iline ait güneş radyasyonu haritası ile arazi kullanım haritası çakıştırılarak tesis kurulumu için arazi uygunluğu ortaya konmaya çalışılmıştır (Şekil 3). Buna göre, Altunhisar ilçesinin kuzeyi, şehir merkezinin güneydoğusu ve Çamardı ilçesinin Doğu kısımlarının güneş enerjisi tesis kurulumu için uygun ve elverişli araziye sahip oldukları görülmektedir. Bu araziler tarımsal ve orman vasfinı yitirmiş olan araziler olup, tesis kurulumu için yasal sınırlama olmayan alanlardır. Bu alanlarda yeterli ve uygun seviyede güneş radyasyonu bulunurken arazi kullanımında tarımsal üretim anlamında herhangi bir kısıtlama bulunmamaktadır [14].

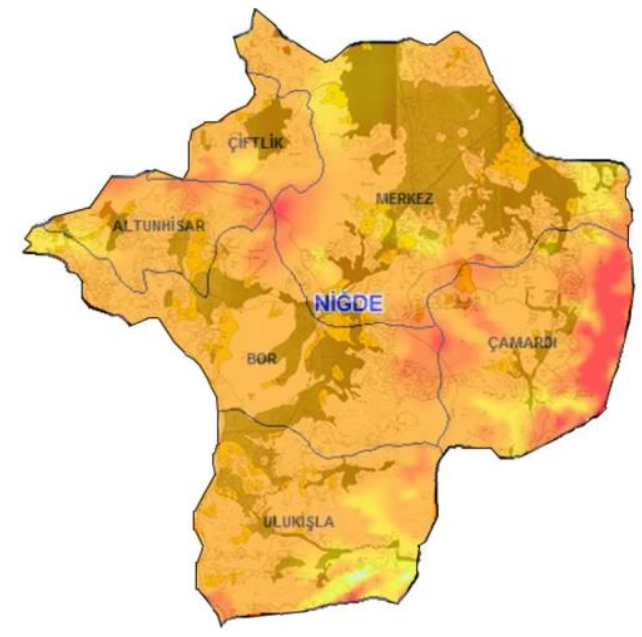

Şekil 3. Niğde ilinde arazi kullanım sınıfları ve güneş enerjisi potansiyeli eşleştirme haritası [14]

Daha önce belirtildiği gibi monokristal silikon paneller birim alan başına en yüksek elektrik verimine sahiptirler (ortalama $27.000 \mathrm{KWH} / \mathrm{y} 1 / 100 \mathrm{~m}^{2}$ ). Türkiye ve Niğde ili için güneş paneli tesislerinin kurulmasının enerji üretimi ve ekonomik kazançlar açısından kayda değer olduğu görülmektedir. Ekonomik boyutta incelendiğinde; $1 \mathrm{MW}$ kurulu güce sahip bir güneş enerjisi tesisi göz önüne alınırsa, böyle bir tesisin ilk yatırım maliyeti yaklaşık 900000 Euro, yıllık işletim maliyeti 5441 ve yıllık elektrik getirisi ise 65655 Euro olmaktadır. $\mathrm{Bu}$ rakamlara göre bir hesap yapıldığında, geri dönüş süresi yaklaşık 13 buçuk yıl olarak hesaplanmaktadır. Bir güneş enerjisi tesisinin ortalama ömrünün 25 y1l olduğu varsayılırsa, bu sürenin sonunda elde edilen kar 752 bin Euro ortalamasında olacaktır. Bir güneş enerjisi tesisinin geri dönüş süresi tesiste kullanılan parçaların birim 
Niğde İlinde Güneș Enerjisi Santrallerinin Kullanımı İle Elektrik Tüketiminden Kaynaklı Sera Gazı Emisyonlarının Azaltılma Potansiyelinin Belirlenmesi

maliyeti, işletme maliyeti gibi parametreler nedeniyle değişkenlik gösterebilmektedir. Tablo 4'te 1 MW Kurulu güce sahip olan güneş enerjisi tesisinin ekonomik değerleri verilmiştir.

Tablo 4. Niğgde ilinde 1 MW güneş enerjisi santrali için ekonomik değerler [14]

\begin{tabular}{|c|c|c|}
\hline Yatırım maliyeti & $€$ & 890.000 \\
\hline İşletme maliyeti & $€ / \mathrm{y} 1 \mathrm{l}$ & 5.440 \\
\hline Yıllık gelir & $€ / \mathrm{y} 1 \mathrm{l}$ & 65.655 \\
\hline Geri dönüş oranı & Yıl & 13,5 \\
\hline Ömrü sonunda elde edilen kar & $€ / \mathrm{y} 1 \mathrm{l}$ & 751.375 \\
\hline
\end{tabular}

Tablo 5'de Niğde ilinin 1 yıllık tükettiği elektrik enerji ihtiyacı için hesaplanan ve gerekli olan güneş enerjisi tesisi kapasitesi ve bu tesis için gerekli olan arazi büyüklükleri verilmiştir.

Tablo 5. Niğde ilinin yıllık enerji ihtiyacının karşılanması için gerekli GES tesisinin hesaplamaları [14]

\begin{tabular}{|c|c|c|}
\hline Yıllık elektrik tüketimi & GWH & 984,4 \\
\hline Tesisin kurulması için gerekli alan & ha & 3.340 \\
\hline Niğde ilinde GES kurulması için uygun alan & ha & 98.175 \\
\hline GES için gerekli alanın toplam elverişli alana oranı & $\%$ & 3,40 \\
\hline Niğde ili elektrik tüketimi için gerekli GES kurulu gücü & MW & 1.670 \\
\hline
\end{tabular}

İlin elektrik ihtiyacı dikkate alınarak yapılan tahminlere ve hesaplara göre Güneş enerjisi tesisi için ihtiyaç duyulan kurulu güç 1670 MW olarak belirlenmiştir. Bunun yanında ihtiyaç duyulan toplam arazi miktarı Niğgde ilindeki güneş enerjisi için elverişli arazinin \% 3,4’üne denk olan 3340 ha alandır.

Niğde ilinde tarımsal ve orman vasfını yitirmiş yaklaşık 98170 ha alan bulunmaktadır. Bu alanın farklı oranlarda güneş enerjisi üretim tesisi için kullanılmasına göre hesap yapıldığında elde edilen sonuçlar tablo 6'da verilmiştir. Güneş enerjisi tesisi kurulabilir elverişli arazinin \%3,4'ü kullanıldığında Niğde ili için 1 yılda ihtiyaç duyulan elektrik enerjisi üretilebilirken, bu arazinin \%10’u kullanıldığında ise Türkiye'nin ihtiyaç duyduğu enerjinin \%1,15'i üretilebilmektedir. Bu arazinin tamamının kullanıldığı varsayıldığında ise Türkiye'nin bir yılda ihtiyaç duyduğu elektrik enerji ihtiyacının \%11,50’si karşılanabilmektedir.

Tablo 6. Niğde ilindeki kullanıma elverişli araziler ve potansiyel elektrik enerjisi üretim değerleri [14]

\begin{tabular}{|c|c|c|c|c|}
\hline Niğde ilindeki GES için elverişli alan kullanım oranı & $\mathbf{1 0 0 \%}$ & $\mathbf{5 0 \%}$ & $\mathbf{1 0 \%}$ & $\mathbf{1 \%}$ \\
\hline GES için elverişli alanı ihtiyacı (ha) & 98.175 & 49087,5 & 9817,5 & 981,8 \\
\hline Yıllık elektrik enerjisi potansiyeli (GWH) & 28.962 & 14.481 & 2.896 & 290 \\
\hline Türkiye'deki yıllık elektrik enerjisi ihtiyacını karşılama oranı (\%) & $\mathbf{1 1 , 5}$ & $\mathbf{5 , 7 4}$ & $\mathbf{1 , 1 5}$ & $\mathbf{0 , 1 2}$ \\
\hline Niğde ilindeki yıllık elektrik enerjisini karşılama oranı (\%) & 2942 & 1471 & 294 & 29,4 \\
\hline Doğal gazdan elde edilen elektrik enerjine oranı (\%) & 24 & 12 & 2,4 & 0,24 \\
\hline Kömürden elde edilen elektrik enerjisine oranı (\%) & 38 & 19 & 3,8 & 0,38 \\
\hline Yenilebilir kaynaklardan elde edilen elektrik enerjisine oranı (\%) & 55 & 27,5 & 5,5 & 0,55 \\
\hline
\end{tabular}




\subsection{Sera gazı emisyonlarının azaltılması potansiyeli}

Türkiye'de elektrik üretimi yenilenebilir ve yenilenemeyen farklı kaynaklar kullanılarak yapılmaktadır. Doğal gaz, ithal kömür, linyit, taşkömürü, hidroelektrik, rüzgar enerjisi ve güneş enerjisi bu kaynakların başında gelmektedir. TÜİK verilerine göre Türkiye'de 2017 yılında kurulu elektrik üretim kapasitesi 83.139 MW olup, elektrik üretimi için kullanılan kaynaklar, bu kaynakların üretime oranları ile enerji değerleri Tablo 7' de verilmiştir.

Tablo 7. 2017 yılında Türkiye'deki farklı kaynaklardan elektrik üretimi kurulu gücü

\begin{tabular}{|c|c|c|}
\hline Elektrik üretim kaynağı & Kurulu güç (MW) & Oran (\%) \\
\hline Doğal gaz & 23.063 & 27,7 \\
\hline İthal Kömür & 8.134 & 9,8 \\
\hline Taş kömürü ve Linyit & 9.873 & 11,9 \\
\hline Hidroelektrik & 27.205 & 32,7 \\
\hline Rüzgar Enerjisi & 6448 & 7,8 \\
\hline Güneş Enerjisi & 14 & 0,01 \\
\hline Çok yakıtlılar & 4052 & 4,9 \\
\hline Diğer (fuel oil, Jeotermal, atık yăg, atık Isı) & 4350 & 5,2 \\
\hline Toplam & 83139 & 100 \\
\hline
\end{tabular}

Özellikle fosil türevli yakıtlar farklı verimlilikte ve kalorifik değerde yanma reaksiyonları gösterdikleri için üretebildikleri birim KWH elektrik enerjisi başına farklı $\mathrm{CO}_{2}$ emisyonlarına neden olmaktadırlar. Bahsedilen fosil türevli her farklı yakıt için ortalama emisyon hesaplamalarında kullanılacak uluslar arası standart değerler "Uluslar Arası İklim Paneli” (IPCC) tarafından yayınlanmaktadır [19]. Tablo 8 de birim elektrik enerjisi üretiminde farklı enerji kaynaklarının neden olduğu $\mathrm{CO}_{2}$ emisyonları verilmiştir. Bu emisyonların hesaplamaları tesislerin yaşam döngüleri göz önüne alınarak yapılmış ve emisyon hesaplamalarında tesislerin inşası, işletilmesi ve ömürlerini tamamladıktan sonra sökülmeleri de dikkate alınmıştır [20]. Fosil türevli yakıtlardan elektrik enerjisi üreten tesislerde en büyük oranda $\mathrm{CO}_{2}$ emisyonları işletme sürecinde oraya çıkarken, yenilebilir enerji kaynaklarından elektrik üretilen tesislerde en yüksek emisyon değerleri tesislerin inşaat ve ömrünün tamamladığında sökülmesi sırasında oluşmaktadır. Bu sebeple yenilebilir enerji kaynaklarının da düşükte olsa bir karbon ayak izi vardır.

Tablo 8. Enerji kaynak türlerine göre birim elektrik enerjisi başına sera gazı emisyonları [20]

\begin{tabular}{|c|c|c|c|}
\hline Kaynak Türü & $\begin{array}{c}\text { Ortalama } \\
\text { Ton } \mathbf{C O}_{2} / \mathbf{G W H}\end{array}$ & $\begin{array}{c}\text { En düşük } \\
\text { Ton } \mathbf{C O}_{2} / \mathbf{G W H}\end{array}$ & $\begin{array}{c}\text { En yüksek } \\
\text { Ton } \mathbf{C O}_{2} / \mathbf{G W H}\end{array}$ \\
\hline Linyit & $\mathbf{1 0 5 4}$ & 790 & 1372 \\
\hline Kömür & $\mathbf{8 8 8}$ & 756 & 1310 \\
\hline Petrol & $\mathbf{7 3 3}$ & 547 & 935 \\
\hline Doğal gaz & $\mathbf{4 9 9}$ & 362 & 891 \\
\hline Nükleer & $\mathbf{2 9}$ & 2 & 130 \\
\hline Hidroelektrik & $\mathbf{2 6}$ & 2 & 237 \\
\hline Güneş enerjisi & $\mathbf{8 5}$ & 13 & 731 \\
\hline Rüzgar enerjisi & $\mathbf{2 6}$ & 6 & 124 \\
\hline Biyokütle enerjisi & $\mathbf{4 5}$ & 10 & 101 \\
\hline
\end{tabular}

Niğde ilinde yıllık tüketilen enerji 984.394 MWH'tir. Bu elektrik enerjisi üretilmesi için Tablo 7'de verilen kaynakların aynı oranda etkidiği varsayıldığında, İlin 1 yılda sebep olduğu $\mathrm{CO}_{2}$ emisyonları toplam 435924,12 ton/yıl olacaktır. Tablo 9'da Niğde ilinin elektrik enerjisi kaynak türlerine göre 1 yılda elektrik enerjisi talebiyle neden olduğu sera gazı miktarları verilmiştir. Çalışmada önerilen GES yenilebilir enerji kaynağı kullanıldığında 
43.5924,12 ton/yıl sera gazları elimine edilmiş, bunun yerine ortalama 25 yıllık ömrü olan 1.670 MW'lık bir GES tesisi için $83.674 \mathrm{TonCO}_{2} / \mathrm{y}$ ll salınımı olacak ve mevcut sera gazı salınımı $\% 81$ oranında azaltılmış olacaktır.

Tablo 9. Niğde ilindeki Elektrik enerjisi üretimlerinin kaynakların oranına göre sebep olduğu emisyon değerleri.

\begin{tabular}{|c|c|c|c|}
\hline Elektrik üretim kaynağı & $\begin{array}{c}\text { Oran } \\
(\mathbf{\%})\end{array}$ & $\begin{array}{c}\text { Niğde ilindeki tüketilen } \\
\text { elektrik enerjisi değeri } \\
\text { KWH/Yıl }\end{array}$ & $\begin{array}{c}\text { Ylllık sera gazı emisyon } \\
\text { değerleri } \\
\text { Ton } \mathbf{C O}_{2} / \mathbf{y l l}\end{array}$ \\
\hline Doğal gaz & 27,7 & 272674 & 136064,51 \\
\hline İthal Kömür & 9,8 & 96470 & 85665,03 \\
\hline Taş kömürü ve Linyit & 11,9 & 117142 & 123467,35 \\
\hline Hidroelektrik & 32,7 & 321894 & 8369,23 \\
\hline Rüzgar Enerjisi & 7,8 & 76782 & 1996,33 \\
\hline Güneş Enerjisi & 0,01 & 98 & 8,37 \\
\hline Çok yakıtlllar & 4,9 & 48235 & 42832,52 \\
\hline Diğer & 5,2 & 51188 & 37520,78 \\
\hline Toplam & $\mathbf{1 0 0}$ & $\mathbf{9 8 4 3 9 4}$ & $\mathbf{4 3 5 9 2 4 , 1 2}$ \\
\hline
\end{tabular}

\section{Tartışma}

Niğde iline ait güneş enerjisi potansiyeli incelenmiş ve yenilenebilir enerji kaynağı olan güneş enerjisi kullanımı ile elektrik üretimi amaçı faaliyetlerden gelen sera gazı emisyonlarının ne derece azaltılabileceği ortaya konmuştur. Bunun yanında ekonomik ve çevresel boyutta faydaları da ele alınmıştır. Kömür ve doğal gaz gibi fosil türevli yakıtlardan kademeli olarak solar enerjiye geçmek Çevre ve iklim değişikliği açılarından zararlı emisyonların azaltılması için gelecek vadeden bir çözümdür. Çevresel kazanca ek olarak stratejik olarak bağımlı olunan doğal gazın tüketimi konusunda da ekonomik fayda sağlanabilecektir.

Yapılan bu araştırma sonuçlarına göre; güneş enerjisi sistemleri yatırımı ile Niğde İlindeki tarım arazisi ve orman vasfını yitirmiş alanın sadece $\% 3,4$ kullanılarak gerekli olan tüm elektrik enerjisi ihtiyacı karşılanabilmektedir. Yerel sınırsız ve temiz enerji kaynağı olan güneş enerji sistemlerinin kullanılması ile bir yandan yeni iş ve çalışma alanları oluşurken, diğer yandan da enerjide olan dışa bağımlılık azalabilecektir. Böylelikle bu sistemler ekonomik ve sürdürülebilir sonuçlar için uzun dönemli avantaj sağlayacaktır.

Çalışma boyunca yasaların solar enerji sistemlerinin kurulmasına müsaade ettiği tarımsal ve ormanlık arazi vasfı dışında olan alanlar, güneş enerjisi tesislerinin kurulması için göz önüne alınarak hesaplamalar bu rakamlar üzerinden yapılmıştır. Böylelikle birinci önceliği olan tarım arazileri ve orman arazileri korunmuştur. Güneş Enerjisi sistemlerindeki Teknolojik gelişmeler, buna bağlı olarak artan üretim miktarı, azalan fiyatlar ve yatırımcı devlet desteğinin artması ile Niğde ilinde güneş enerjisi projeleri gelecekte artabilecektir. Bu artışla birlikte İlde doğa dostu sürdürülebilir ve yenilenebilir elektrik enerjisi üretimi artabilecektir.

Yapılan bu araştırmanın sonuçlarına göre; güneş enerjisi ve yenilenebilir enerji ile ilgili kurumlar ve organizasyonların iş birliği, yasal düzenlemeler ve politikaların da desteğiyle temiz enerji üretimi ve güneş enerjisi tesislerinin projeleri desteği teşvik edilmelidir. Bu teşvikler sonunda yapılabilen yatırımlar ile iklim değişikliği ile mücadelede, hava kalitesinin korunmasında ve yerel enerji kaynaklarının korunması konularında çok yönlü fayda ve kazanç sağlanacaktır.

Yatırımcıların teşvik edilebilmesi ve daha net bir provizyonun ortaya konabilmesi için yüksek verimlilikte enerji üretimlerini sağlayabilen ayrıntılı enerji performans oranlarına sahip, tarım dışı ve orman dışı arazilerde daha kapsamlı araştırmalar yapılması gerekmektedir. Bu çalışmaların yanında ülkedeki enerji üretimi için tarımsal ve hayvancılık ekonomisinden farklı bir şekilde desteklenecek olan enerji üretiminin bir çekim noktası olarak yatırımcıların dikkatini çekmek için hükümet ve özel kuruluşlarla işbirliği yapılması önerilmektedir. Bu araştırmadan elde edilen verilere göre; teknolojik gelişmeler, maliyetlerin azalması ve yatırımcı-devlet destekleri sayesinde Niğde ilinde GES projelerine daha fazla önem verilebileceği ve mevcut enerji üretiminin ekonomik olarak artabileceği sonucuna ulaşılmıştır. 


\section{Kaynaklar}

[1] Košir, M., Iglič, N., Kunič, R.: Optimisation of heating, cooling and lighting energy performance of modular buildings in respect to location's climatic specifics. Renew Energy 2018; 129: 527-539.

[2] Abo-Elyousr, F.K., Elnozahy, A.: Bi-objective economic feasibility of hybrid micro-grid systems with multiple fuel options for islanded areas in Egypt. Renew Energy 2018; 128: 37-56.

[3] Gu, Q., Wei, J., Luo, S., Ma, M., Tang, X.: Potential and environmental control of carbon sequestration in major ecosystems across arid and semi-arid regions in China. Sci Total Environ 2018; 645: 796-805.

[4] Nabielek, P., Dumke, H., Weninger, K.: Balanced renewable energy scenarios: a method for making spatial decisions despite insufficient data, illustrated by a case study of the Vorderland-Feldkirch Region, Vorarlberg, Austria. Energy Sustain Soc.8, 2018.

[5] Üçtuğ, F.G., Azapagic, A.: Environmental impacts of small-scale hybrid energy systems: Coupling solar photovoltaics and lithium-ion batteries. Sci Total Environ 2018; 643: 1579-1589.

[6] Leng, G.: Keeping global warming within $1.5^{\circ} \mathrm{C}$ reduces future risk of yield loss in the United States: A probabilistic modeling approach. Sci Total Environ 2018; 644: 52-59.

[7] Talbot, D., Boiral, O.: GHG reporting and impression management: An assessment of sustainability reports from the energy sector. J Bus Ethics 2018; 147: 367-383.

[8] Karunathilake, H., Hewage, K., Mérida, W., Sadiq, R.: Renewable energy selection for net-zero energy communities: Life cycle based decision making under uncertainty. Renew Energy 2019; 130: 558-573.

[9] Ediger, V.Ş., Kirkil, G., Çelebi, E., Ucal, M., Kentmen-Çin, Ç.: Turkish public preferences for energy. Energy Policy 2018; 120: 492-502.

[10] Liobikienè, G., Butkus, M.: The challenges and opportunities of climate change policy under different stages of economic development. Sci Total Environ 2018; 642: 999-1007.

[11] Kılıç, E., Puig, R., Zengin, G., Zengin, C.A., Fullana-i-Palmer, P.: Corporate carbon footprint for country Climate Change mitigation: A case study of a tannery in Turkey. Sci Total Environ 2018; 635: 60-69.

[12] Ozdemir, S., Sahin, G.: Multi-criteria decision-making in the location selection for a solar PV power plant using AHP. Meas J Int Meas Confed 2018; 129: 218-226.

[13] Pasaoglu, G., Garcia, N.P., Zubi, G.: A multi-criteria and multi-expert decision aid approach to evaluate the future Turkish power plant portfolio. Energy Policy 2018; 119: 654-665.

[14] Sak, T.: Rüzgâr ve güneş enerjisi teknolojilerinin irdelenmesi ve Niğde iline uygulanabilirliklerinin değerlendirilmesi, Yüksek lisans, Niğde Ömer Halisdemir Üniversitesi, Niğde, Turkiye, 2015.

[15] Koval, S., Krahenbuhl, G., Warren, K., O’Brien, G.: Optical microscopy as a new approach for characterising dust particulates in urban environment. J Environ Manage 2018; 223: 196-202.

[16] Yang, H.-H., Arafath, S.M., Lee, K.-T., Hsieh, Y.-S., Han, Y.-T.: Chemical characteristics of filterable and condensable PM2.5 emissions from industrial boilers with five different fuels. Fuel 2018; 232. 415-422.

[17] Gonzalez, A., Riba, J.-R., Esteban, B., Rius, A.: Environmental and cost optimal design of a biomass-Wind-PV electricity generation system. Renew Energy 2018; 126: 420-430.

[18] Souliotis, M., Arnaoutakis, N., Panaras, G., Kavga, A., Papaefthimiou, S.: Experimental study and Life Cycle Assessment (LCA) of Hybrid Photovoltaic/Thermal (PV/T) solar systems for domestic applications. Renew Energy 2018; 126: 708723.

[19] Ramphull, M., Surroop, D.: Greenhouse gas emission factor for the energy sector in Mauritius. J Environ Chem Eng 2017; 5: 5994-6000.

[20] WNA: Comparison of Lifecycle Greenhouse Gas Emissions of Various Electricity Generation Sources, 2011. 